\title{
GEOLINGÜÍSTICA E CONHECIMENTO DA SÓCIO-HISTÓRIA DO PORTUGUÊS DO BRASIL
}

Vanderci de Andrade AGUILERA

Universidade Estadual de Londrina/CNPq

Resumo: Este artigo busca, nos primeiros atlas publicados e nos últimos estudos geolingüísticos de quatro regiões distintas (Adrianópolis-PR, Litoral Sul Paulista, Ilha de Marajó-PA e Ponta Porã - MS), a comprovação da importância dos atlas lingüísticos para auxiliar na compreensão da sócio-história do português brasileiro.

Palavras-chave: português brasileiro, atlas lingüísticos, variação lexical.

Abstract: This article searchs, in first published linguistic atlases and in the lastest geolinguistic studies in four distinct regions (AdrianópolisPR, Litoral Sul Paulista, Ilha de Marajó-PA e Ponta Porã - MS), to check the importance of linguistic atlases for assisting in understanding the socio-history of Brazilian Portuguese.

Key words: Brazilian Portuguese, linguistic atlases, lexical variation.

Resumen: Este artículo realiza una búsqueda, en los primeros atlas lingüísticos y en los últimos estudios geolingüísticos desarrollados en cuatro regiones brasileñas distintas (Adrianópolis-PR, Litoral Sul Paulista, Ilha de Marajó-PA e Ponta Porã - MS), con el fin de comprobar la importancia de los atlas lingüísticos en lo que se refiere a su aportación para la comprensión de la historia social del portugués brasileño.

Palabras-clave: portugués brasileño, atlas lingüístico, variación léxica.

\section{Introdução}

A geolingüística, apesar dos ingentes esforços de estudiosos da linguagem do Brasil, como Nascentes (1958 e 1961) e Silva Neto (1957), começou em nosso país timidamente, em 1963, com um único atlas publicado - o Atlas Prévio dos Falares Baianos (ROSSI, 1963) APFB -, isto é, atlas de um estado dentre os vinte estados brasileiros existentes à época. Sua caminhada também se fez a passos lentos por quase quarenta anos. No apagar das luzes do segundo milênio e 
princípios do terceiro, passa a viver um período de grande euforia, haja vista que, a cada ano, desde 1996 com a Carta da Bahia, em que um grupo de pesquisadores propôs a elaboração de um Atlas Lingüístico do Brasil, pontilham novos atlas ${ }^{1}$ ou projetos deles no cenário das pesquisas sobre a distribuição espacial, ou diatópica. Cito, a título de exemplo, o Atlas Lingüístico do Mato Grosso do Sul ALMS - em fase de conclusão, e os projetos dos atlas do Maranhão ALIMA-,do Rio Grande do Norte - ALIRN-, do Mato Grosso ALIMAT-, do Espírito Santo - ALES, dois projetos para o Rio de Janeiro e a mais recente boa nova, o projeto do Atlas Lingǘstico de Rondônia, o ALiRO, de Teles (2006).

Dentre esses novos atlas de maior abrangência geográfica os que recobrem um estado ou uma região, como o Atlas Lingüístico e Etnográfico da Região Sul - ALERS e o Atlas Lingüístico Sonoro do Pará - ALiSPA, publicados em 2002, e o Atlas Lingüístico de Sergipe II - ALS II - publicado em 2005, juntamente com o Atlas Lingüístico do Amazonas - ALAM - tese defendida nesse mesmo ano, emergem diversos outros atlas, frutos de teses e de dissertações, que recobrem extensões territoriais menores, como o Atlas Lingüístico da Ilha de Santa Catarina (IMAGUIRE: 1999), Atlas Lingüístico de Adrianópolis (ALTINO, 2002), Atlas Lingǘstico da Ilha de Marajó (CARDOSO SILVA: 2002), Atlas Lingüístico do Litoral Paulista (IMAGUIRE: 2003), e o Atlas Lingǘstico do município de Ponta Porã - MS (REIS: 2006). Sobre algumas cartas desses quatro últimos é que este trabalho trata, tomando-se como referência teórica as considerações de Coseriu (1987).

Para início, é sempre bom lembrar o que são os atlas lingüísticos e que aspectos possibilitam explorar, que documento, na seqüência, com os registros de atlas publicados até 1994, no caso, os cinco primeiros: APFB, EALMG, ALP, ALS e ALPR.

\section{Atlas lingüísticos: o que são e para que servem}

Numa definição simplista pode-se dizer que os atlas são uma coletânea de mapas de um dado território sobre os quais se registra

\footnotetext{
${ }^{1}$ Informações mais completas sobre a geolingüística no Brasil encontram-se em: AGUILERA, Vanderci de Andrade (Org.) A geolingüistica no Brasil: trilhas seguidas, caminhos a percorrer (2005).
} 
graficamente a distribuição de determinados fenômenos léxicos, fonéticos, morfológicos, sintáticos, entre outros. Coseriu, porém, os conceitua como sendo,

essencialmente uma coleção de material, dado que permitem comprovar a própria existência duma forma, fato que se considera particularmente importante se se trata da persistência duma forma antiga, substituida porformas mais recentes na maioria dos falares investigados. Quer dizer, o atlas lingüistico constitui, em primeiro lugar, um valioso inventário de formas. (COSERIU, 1987, p. 93)

Para ratificar a assertiva de Coseriu, e consultando algumas cartas dos cinco primeiros atlas publicados, verifica-se que determinados registros revelam variantes léxicas populares em processo de arcaização, introduzidas nos primeiros anos do contato do europeu com os grupos indígenas e africanos. A título de ilustração, para arco-íris constam, entre outras, arco-da-velha, presentes no APFB, no EALMG, no ALS e no ALPR; olho-de-boi no APFB, ALS e ALPB. No nível fonéticofonológico, são fartos os exemplos, nesses atlas, de formas não mais existentes na fala urbana padrão, como as formas nasalizadas [lũa, lũma] por lua, ou desnasalizadas e/ou dissimiladas, como lebrina, lubrina por neblina; ou reduzidas, como grana, landra por glândula.

Esses exemplos lembram Silva Neto (1970, p. 593) quando assevera:

O Brasil ainda hoje representa um conjunto de duas épocas estratificadas. No "sertão" encontraremos um quadro arqueológico da nossa civilização colonial no que diz respeito a raça, economia, costumes, folclore, mística. Não será muito exagerado dižer que em algumas regiões achamos os séculos XVII e XVIII.

$\mathrm{Na}$ esteira do pensamento de Coseriu (1987, p. 94) - se se podem constituir séries de muitos casos análogos, os atlas permitem, antes de mais nada, inducooes de indole histórica a respeito do caráter "conservador" ou "inovador" dum dialeto. A recorrência dos fatos lexicais e fonéticos apresentados acima e extraídos de atlas que, na maioria dos casos, se pautaram na fala rural, deixa evidente o caráter conservador do dialeto rural em suas diversas modalidades pelas várias regiões brasileiras. 
Outra função dos atlas, discutida pelo lingüista romeno, é a possibilidade de fazer inducões também de caráter geral: por exemplo, que as formas ou fases mais antigas se conservam com mais freqüencia em zonas isoladas, longe das grandes vias de comunicação (COSERIU, 1987, p. 94). Ilustro com a variante mãe-do-corpo para útero que sobrevive apenas nos pontos 10, 34, 36, 46 e 48, localizados nas partes sul, sudeste e sudoeste da Bahia, distantes da capital, mas próximos da divisa com Minas Gerais. A variante mãe do corpo não representa qualquer ameaça a dona-do-corpo, forma hegemônica em quase todas as regiões baianas rurais.

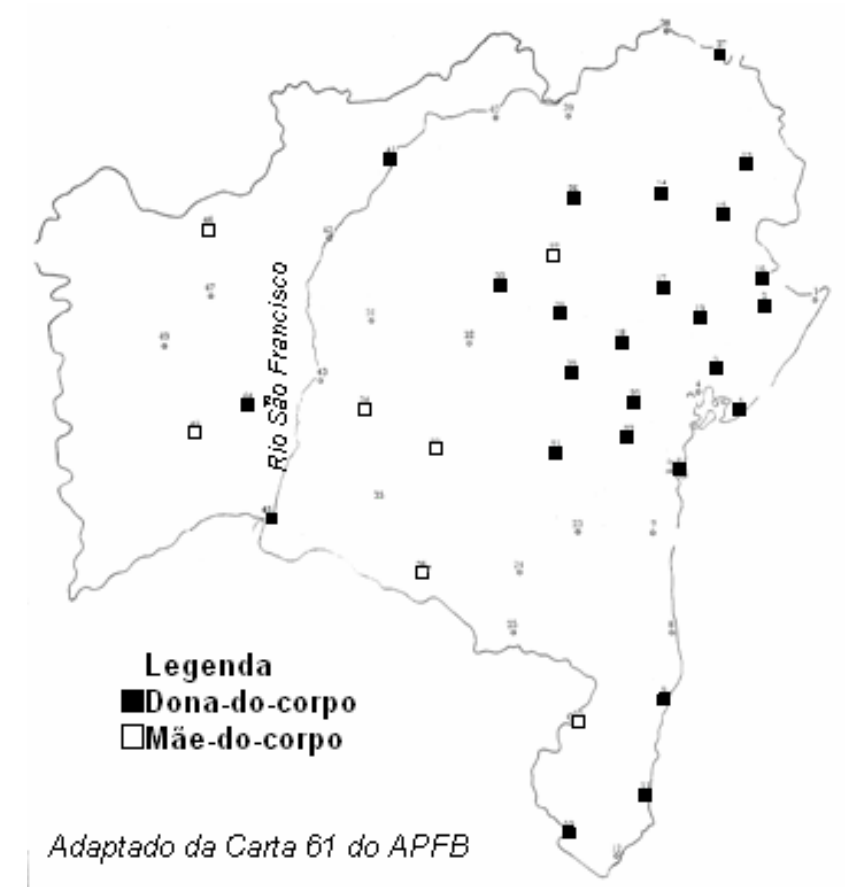




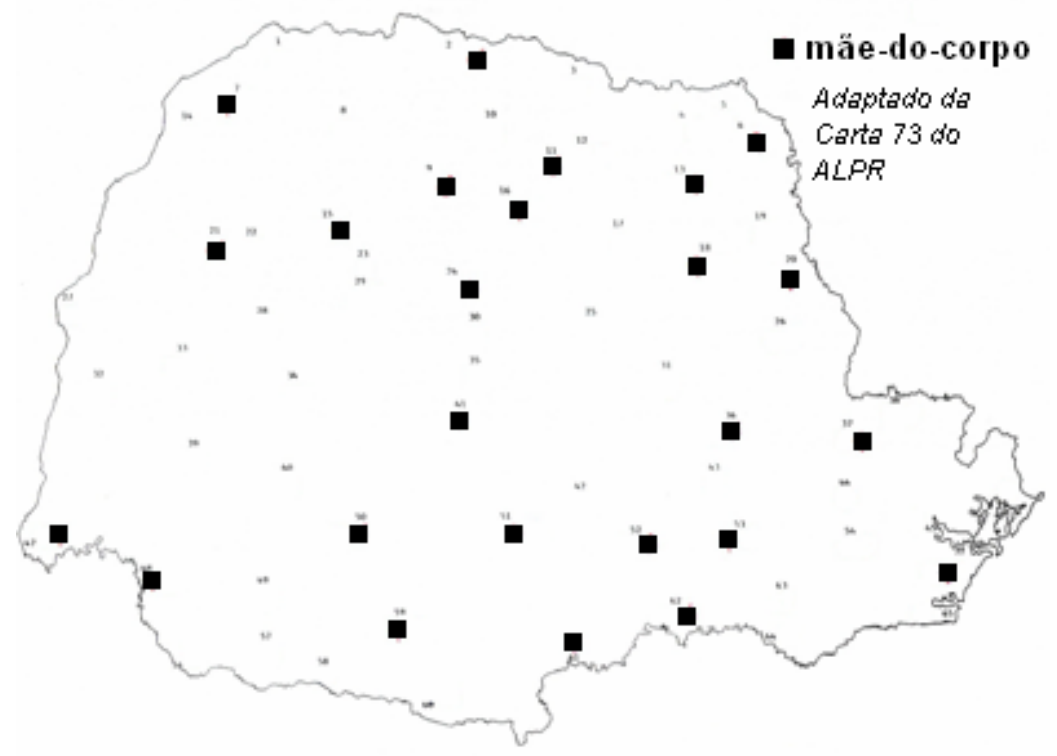

Coseriu salienta outras possíveis reflexões sobre as funções dos atlas quando se refere às inovações na língua. Neste aspecto, podemse levantar hipóteses de base histórica e geográfica, tais como:

a partir de que centro se difundiu uma inovação (por exemplo, duma cidade importante, de particular prestígio cultural e politico) e até onde chegou ela; quais são os seus limites, os obstáculos que detiveram a sua difusão; quais foram, em geral, os centros inovadores num território e quais as resistências às inovações. [...] Em segundo lugar, induções de indole geral: as inovações se difundem ao longo das grandes vias de comunicação, seguindo, por exemplo o vale dos rios e amiúde passam duma cidade a outra sem conquistar as zonas intermediárias. (COSERIU, 1987, p. 95)

A propósito de induções históricas a partir da distribuição diatópica de algumas variantes, Aguilera (2005) analisou uma série de variantes léxicas do campo dos brinquedos e brincadeiras infantis e concluiu que esse campo léxico dos brinquedos e brincadeiras infantis 
cartografados nos sete atlas estaduais delineia-se como um corpus bastante produtivo que permite associar a linguagem de transmissão oral aos movimentos sociais e, assim, comprovar: (i) a importância dos bandeirantes e garimpeiros paulistas na disseminação da modalidade oral da língua portuguesa falada nos primeiros séculos da história do povoamento. Documentamos com a trajetória de algumas variantes léxicas como cambota (cambalhota) registrada no interior de Minas Gerais e da Bahia ao longo do rio São Francisco e pelas regiões de mineração;

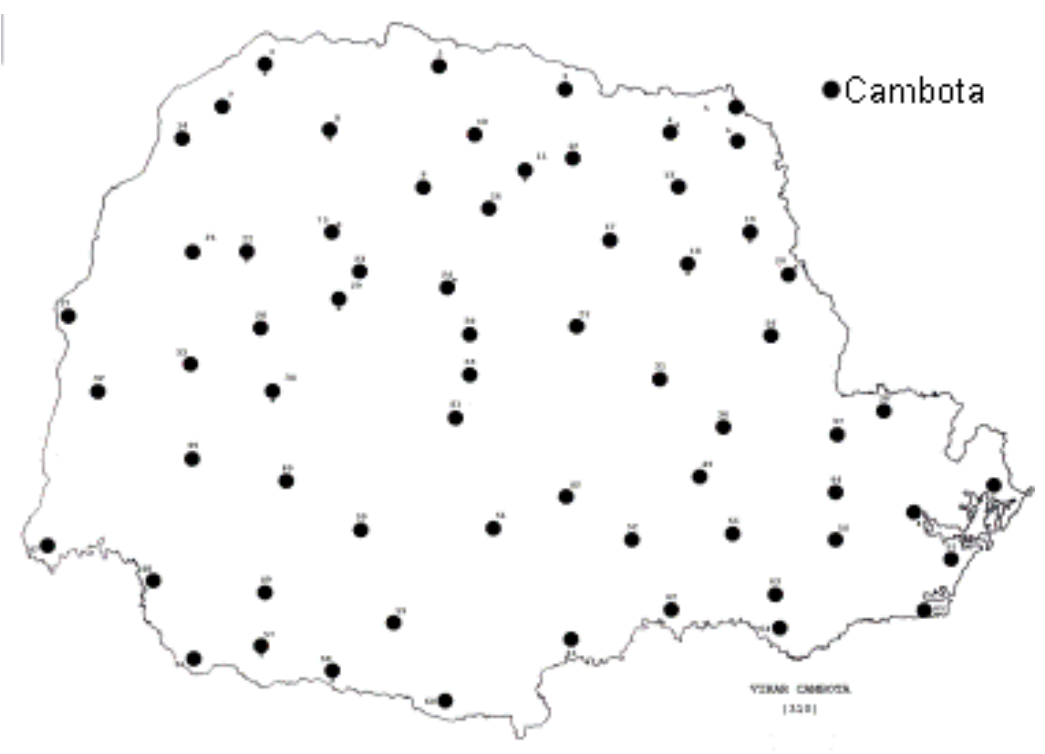




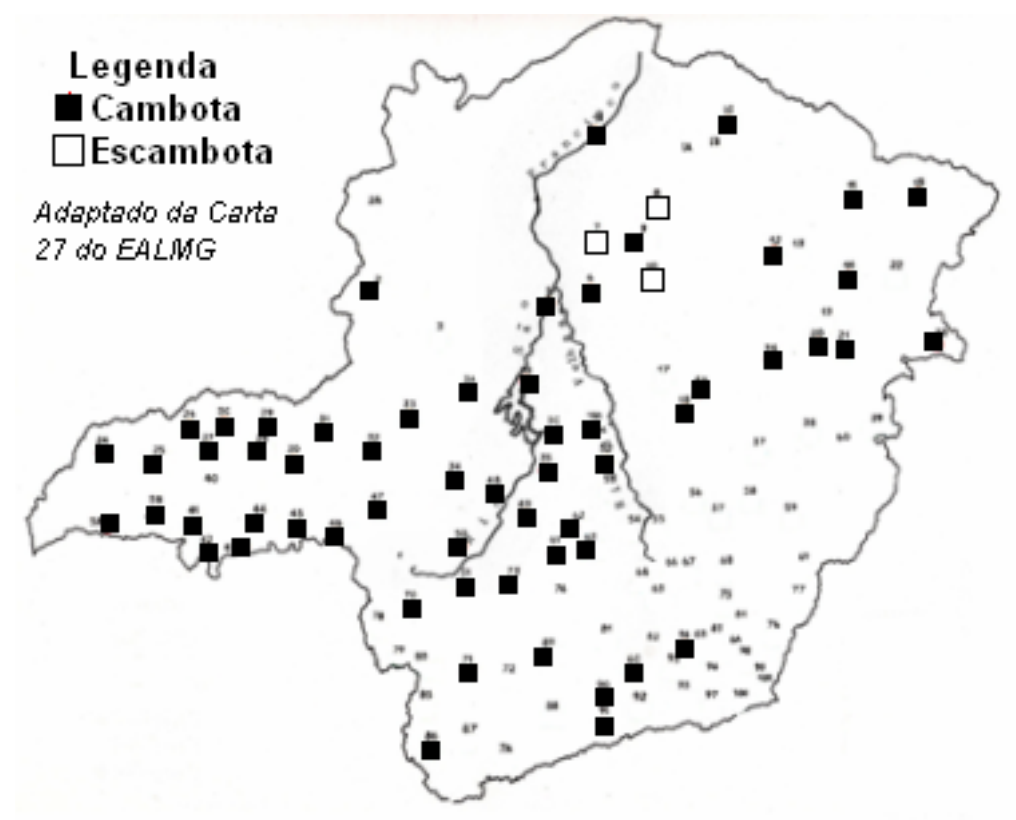

(ii) a presença de variantes mais antigas, como bodoque, funda, besta e seta, para o brinquedo de atirar pedra, feito de forquilha, borracha e couro, as quais, no decorrer de sua história, e devido a condicionantes históricoculturais, perderam alguns semas originais e receberam outros ao nomear referentes distintos, às vezes até com traços semânticos diferenciados. No caso de bodoque, por exemplo, citado por Isquerdo (2005), alguns traços foram mantidos: objeto de arremessar à distância, bola, arma. Esse processo de alteração semântica, observado com relação ao item lexical bodoque, é destacado por Mario Alinei, semanticista italiano e pesquisador do Atlas Linguarum Europae - ALE, que defende a tese de que a nomeação de um novo referente é sempre resultado de um conjunto ordenado de traços (Alinei, 1984). Igualmente, seta manteve os semas arma, arremessar à distância, impulsão por um artefato de madeira e material elástico, em que o arco é substituído por um artefato sob a forma de uma forquilha; (iii) a expansão de lexias de outros campos léxicos como salto/pulo mortal (atividade física ou circense), pirueta (aviação) inserindo-se na fala dos seis estados analisados, num mundo cada vez mais globalizado; (iv) a presença de variantes inovadoras, formando áreas de isoléxicas, como estilingue, pipa e 
cambalhota, resultantes da influência que os grandes centros urbanos exercem sobre o interior e sobre outras regiões; (v) a tese de Nascentes (1953) de que a Bahia se coloca como um divisor entre os falares do Norte e do Sul, como nas variantes essencialmente nortistas, como canastral bunda canastra, escambona / maria-escambona (cambalhota); pira, manja (brincadeira de correr para pegar); baladeira / baleadeira, (atiradeira), peteca (bolinha-de-gude e estilingue); marraio (bolinha-degude); e nas essencialmente sulistas como pique, mãe, pega-pega, salva (brincadeira de correr para pegar); estilingue, (atiradeira), pandorga (papagaio); (vi) a gradativa extinção ou restrição de espaço geográfico de variantes regionais como boldando, coqueiro, capoeira (cambalhota), bila, china, bolinha-de-crica, fona/bolinha-de-fona (bolinha-de-gude); (vii) a existência de palavras polissêmicas, isto é, uma lexia denomina vários referentes: peteca que, em determinadas regiões do Brasil tanto nomeia o brinquedo feito originalmente de palha dobrada que se joga com a palma da mão; como a bolinha de vidro e o estilingue.

Em síntese, verifiquei que a expansão, a concentração, a intersecção e o desaparecimento de formas lingüísticas num dado espaço geográfico são condicionadas pela história social da região, pelas características étnicas da população e por condicionantes sócio-históricogeográficos que determinam a forma de viver e de pensar de um grupo social. Neste caso, os dados demonstraram, como é notório, que as palavras não viajam sós, elas acompanham os homens em sua constante mobilização espacial, levados pela necessidade de buscar novos horizontes e novas experiências.

2 Atlas mais recentes e a aplicação dos dados geolingüísticos à história da movimentação do homem pelo espaço territorial.

Pelos caminhos da geolingüistica paranaense: um estudo do léxico popular em Adrianópolis (ALTINO, 2002), apresentado inicialmente como dissertação de mestrado, consta de 107 cartas lexicais, do tipo analíticosintético. Um dos objetivos dessa pesquisa foi verificar, mediante a comparação dos dados coletados em 1987 e registrados por Aguilera (1994), as possíveis ocorrências de variações e de mudanças no vocabulário oral de falantes pouco escolarizados. A comparação das cartas comuns a ambos os atlas apontou para a manutenção das variantes registradas por Aguilera, principalmente no que se refere à resistência 
de lexias: (i) de base tupi como inconha (bananas grudadas), jojoca (soluço), picumã (fuligem); (ii) do português rural de caráter arcaizante, como funil (redemoinho); queixal (dente molar), náfego (manco), fuzilo (relâmpago), arco-de-velho(a) (arco-íris), cuitelo (beija-flor); visagem (aparição, fantasma), farolete (lanterna); (iii) regionais do sul paranaense, resultantes do contato com catarinenses e gaúchos, como maçanilha (camomila), mimosa (tangerina), bainha (vagem do feijão), aipim (mandioca). Algumas inovações se mostraram bastante significativas: a presença de passarela, para pinguela, resultante das soluções governamentais paliativas para resolver os estragos das enchentes do rio Ribeira que levavam corredeira abaixo a ponte construída precariamente e substituída, quase sempre, por uma passarela provisória; e a ocorrência de bic por isqueiro, usando a marca pelo produto, e semáforo, forma erudita, ao lado de sinal e sinaleiro.

O exame dessas cartas confirmou duas hipóteses: a da resistência lingüística a mudanças em localidades isoladas geograficamente e a inovação lexical condicionada a fatores do contexto social.

A tese $O$ Estudo semântico-lexical com vistas ao Atlas Lingüistico da mesorregião do Marajó/Pará (SILVA, 2002) consta de 207 cartas do tipo analítico-sintético. Um dos objetivos da pesquisa era verificar, mediante a comparação de variantes sugeridas ${ }^{2}$ nos Questionários do ALiB - 2001, os dados coletados por SILVA em cinco localidades da ilha paraense (Anajás, Melgaço, Breves, Chaves e Soure). A maioria das cartas traz, como formas predominantes no vocabulário da ilha, variantes lexicais e fonéticas regionais do Norte, como: igarapé (rio pequeno), mangará (ponta do cacho da banana), macaxeira (mandioca), carapanã (pernilongo), turu (bicho de pau podre), tapuru (bicho de fruta), mucura (gambá) jacinta (libélula) e mucho (mocho, boi sem chifre). As cartas apontam também a co-ocorrência de variantes do português médio, como boca da noite,

\footnotetext{
${ }^{2}$ Os Questionários do ALiB -2001, bem como as versões de 1998 e 2000, trazem na cabeça de cada pergunta do Questionário Fonético Fonológico QFF - a única resposta aceitável para efeito de análise da distribuição espacial das variantes fonéticas de determinados sons selecionados para aquele contexto. Introduzindo as perguntas do Questionário Semântico-Lexical - QSL- traz sugestões - nada mais que sugestões - de possíveis variantes para o conceito buscado naquela questão.
} 
chuva de pedra, estrela cadente, estrela dalva; outras do português popular rural, como caminho de santiago, palma (penca de banana), imbigo (ponta roxa do cacho da banana), coiteiro (trabalhador de enxada em roça alheia), espinhaço (lombo de animal), cabelouro (crina do animal), rejeito (calcanhar). Em alguns casos, formas de prestígio são introduzidas, mas revestidas de uma camada sonora especial como covitiviti (conjuntivite), oxilas (axilas), catabrata, cacarata (catarata).

A dissertação Estudo com vistas a um Atlas Lingüístico da Ilha de Santa Catarina. Abordagem de aspectos semânticos lexicais (IMAGUIRE, 1999) é constituído por 100 cartas lexicais, do tipo analítico-sintético e 10 do tipo sintético. Em sua pesquisa, a autora delimitou trinta e cinco localidades e aplicou um questionário baseado no do Atlas Lingǘrtico do Estado de São Paulo - ALESP - (CARUSO, 1982). A maioria das cartas traz, como formas predominantes no vocabulário da ilha, variantes lexicais regionais do Sul, como: lomba (morro), pevide (semente), cana-limão (capim cidreira), chincha (baixeiro), carocha (besouro), beleza (costeleta), funda (estilingue), pandorga (papagaio de papel), burra (gangorra). As cartas apontam também a co-ocorrência de variantes do português médio, como pipa (papagaio de papel), costeleta, míope, vesgo, sutiã, az̧ia; outras do português popular rural, como cuitelinho, caminho de santiago, palma (penca de banana), imbigo (ponta roxa do cacho da banana), capenga (coxo, que coxeia), leicenço (furúnculo), baga-do-adão (pomo-de-adão), garrão (calcanhar), capela-do-olho (pálpebras), queixal (dente molar). Em alguns casos, formas de prestígio ou urbanas são introduzidas, embora pouco produtivas, como zorba, estilingue, gangorra, coriza, molares.

Outra pesquisa geolingüística, recentemente defendida também sob a forma de dissertação de mestrado - o Atlas Lingüístico do município de Ponta Porã - MS: um registro das linguas em contato na fronteira do Brasil com o Paraguai (REIS, 2006), investigação levada a efeito em oito pontos do interior do município, apresenta uma coletânea de 232 cartas, do tipo analítico-sintética. A autora destaca como objetivos (i) registrar a modalidade oral da língua portuguesa em sua variante sulmatogrossense; (ii) documentar possíveis mudanças lingüísticas na língua falada; (iii) registrar marcas de conservadorismo e de bilingüismo nas línguas em contato (português, espanhol e guarani) na fronteira. Considerando que Ponta Porã foi cenário da Guerra do Paraguai (18641870), reconhece a possibilidade de o fato ter gerado intensas trocas 
culturais e lingüísticas nessa faixa do território dando-lhe, especialmente na língua falada, fisionomia própria, distinta de outras regiões do Mato Grosso do Sul. Como o questionário aplicado previa a indagação pelo nome em guarani e em espanhol, a maioria das cartas documenta variantes das três origens, como: brejo, estero, karovu, karoguá, tuju (terreno úmido); círculo, anillo, akariju (roda em volta da lua); chuva de verão, chaparrón, ama (chuva rápida); chuva de pedra, lluva de bielo, amandaú (chuva de granizo); mexerica, mandarina, aratipy (tangerina); cogumelo, hongo, pombero, yrupero, kamambanambi (cogumelo). A autora conclui que

A pesquisa documentou: (i) a forte influência do guarani, como lingua nativa usual na fronteira, que suplantou o uso do espanhol, lingua transplantada; (ii) o entrelaçamento do português com os idiomas da fronteira, gerando grande incidência de termos híbridos de base portuguesa, guarani e espanbola, como estrella guia (espanhol/português), arroyo yrembe'y (margem de rio espanbol / guarani), além de (iii) termos regionais e arcaísmos (ikoe, ikõm, mellizo, gêmeas (bananas grudadas em guarani/ espanbol/português, respectivamente).

\section{Conclusões}

Parafraseando Oliveira (2001, p. 402), sabemos que em nenhum lugar a história estará pronta, à espera da mão do geolingüista para colhê-la, mas que se faz necessário aprender modos de historicizar os conceitos que utilizamos, além de desenvolver modos de historicizar o nosso fazer disciplinar. Dessa forma, tomando dados lexicais de atlas de grande amplitude, no caso os estaduais, e os de menor abrangência, como os municipais (Adrianópolis, Florianópolis e Ponta Porã) e os de médio alcance como o da Ilha de Marajó - que, na realidade, ocupa um espaço territorial maior do que muitos estados brasileiros - é possível falar da história dos grupos humanos que povoaram e povoam as regiões estudadas. Neste trabalho foi possível elencar variantes léxicas (i) de línguas estrangeiras, como o espanhol, em contato com os falares locais; (ii) do português de épocas anteriores, de caráter mais rural e conservador; (iii) contribuições de línguas indígenas autóctones, como o guarani e o tupi; (iv) além das inovações 
léxicas que se vão agregando ao tesouro vocabular de uma língua, testemunhando a presença do homem e os momentos históricos de cada comunidade e, assim, incluindo a nomenclatura de todos os conceitos lingüísticos e não lingüisticos e de todos os referentes do mundo físico e do universo cultural do presente e do passado da sociedade. (BIDERMAN, 1992, p. 399).

\section{Referências}

AGUILERA, Vanderci de Andrade. (Org.). A geolingüistica no Brasil: trilhas seguidas, caminhos a percorrer. Londrina: Eduel, 2005.

ALINEI, Mário. Le due strutture del significato. In: Lingua e dialetti: struttura, storia e geografia. Bologna: Ed. Il Mulino, 1984. p. 13-21.

ALTINO, Fabiane Cristina. Pelos caminhos da geolingüistica paranaense: um estudo do léxico popular em Adrianópolis. 2001. 218p. Dissertação (Mestrado em Letras) - Universidade Estadual de Londrina, Londrina. 2v. (Versão em CD-Rom, 2006)

BIDERMAN, Maria Tereza Camargo. O léxico, testemunha de uma cultura. Fundación "Pedro Barrié de La Maza, Conde de Fenosa", A Coruña, 1992.

COSERIU, Eugênio. O homem e sua linguagem. 2. ed. Rio de Janeiro: Presença, 1987. (Coleção Linguagem, 16)

IMAGUIRE, Ligia Maria. Estudo com vistas a um Atlas Lingüistico da Ilha de Santa Catarina. 1999. 554f. Abordagem de aspectos semânticos lexicais. (Mestrado em Lingüística) - Universidade de São Paulo, São Paulo. 2v.

ISQUERDO, Aparecida Negri. Designações para estilingue em atlas lingüísticos brasileiros: perspectivas diatópica e sócio- histórica. Actes du XXIVe CILPR. Aberystwyth, UK, 2005. (no prelo)

NASCENTES, Antenor. Bases para a elaboração do Atlas Lingüístico do Brasil. Rio de Janeiro: Casa de Rui Barbosa, 1961. 
Bases para a elaboração do Atlas Lingüistico do Brasil. Rio de Janeiro: Casa de Rui Barbosa, 1958.

OLIVEIRA, Gilvan Müller de. Matrizes da língua portuguesa no Brasil meridional: 1680-1830. In: MATTOS E SILVA, Rosa Virgínia (Org.). Para a bistória do português brasileiro - vol. II: primeiros estudos, tomo II. São Paulo: Humanitas/FFLCH/USP: FAPESP, 2001.

REIS, Regiane C. P. Atlas Lingüistico do município de Ponta Porã-MS: um registro das línguas em contato na fronteira do Brasil com o Paraguai. 2006. 463f. Dissertação (Mestrado em Letras) - Universidade Federal de Mato Grosso do Sul, Três Lagoas. 2v.

ROSSI, Nelson; FERREIRA, Carlota; ISENSEE, Dinah. Atlas Prévio dos Falares Baianos (APFB). Rio de Janeiro: INL-MEC, 1963.

SILVA, Maria do Perpétuo Socorro Cardoso da. Estudo semântico-lexical com vistas ao Atlas Lingüístico da mesorregião do Marajó/Pará. 2002. 455f. Tese (Doutorado em Lingüística) - Universidade de São Paulo, São Paulo. 2v.

SILVA NETO, Serafim da. Guia para estudos dialectológicos. 2. ed. Belém: CNPq / Instituto Nacional de Pesquisas da Amazônia, 1957. 